\title{
Celebridades, acontecimentos e valores na sociedade contemporânea
}

\section{Paula Guimarães Simões}

Universidade Federal de Minas Gerais, Belo Horizonte, Minas Gerais, Brasil

\section{Vera Regina Veiga França}

Universidade Federal de Minas Gerais, Belo Horizonte, Minas Gerais, Brasil

\section{Resumo}

A proposta deste artigo é refletir sobre a presença das celebridades na cena contemporânea, tendo em vista as ações realizadas em acontecimentos que as projetam na cena pública e que revelam valores da sociedade em que se inscrevem. O referencial teórico articula as noções de celebridades, valores e acontecimentos. $O$ corpus é composto por 18 ocorrências selecionadas em um laboratório de análise de acontecimentos tendo em vista duas categorias: acontecimentos que tratam da vida privada e de questões de gênero. A análise revela valores-princípio que sustentam as ações das celebridades, bem como disputas que se processam em torno dos afetos presentes na celebrização dos famosos.

\section{Palavras-chave}

Celebridades. Acontecimentos. Valores.

\section{Introdução}

Um primeiro esclarecimento a ser feito na apresentação deste texto é sua própria origem e objetivos. Tomando como referência o conceito de acontecimento e seu poder hermenêutico (sua capacidade de provocar sentidos e acionar questões da vida social) ${ }^{1}$, nosso grupo de pesquisa ${ }^{2}$ desenvolve um projeto de extensão que consiste na publicação de um site de registro e leitura das ocorrências de maior destaque na mídia tradicional e redes sociais. Esse laboratório de análise de acontecimentos - Grislab foi criado em outubro de 2013. Em dezembro de 2017, desenvolvendo um balanço de nosso percurso em quatro anos, fizemos um levantamento das análises produzidas no período, buscando identificar, entre outros aspectos, as temáticas mais presentes. Foram produzidas no período 253 
análises, tratando de diferentes assuntos. A temática mais presente, com 79 análises, foi política (o que era de se esperar, considerando o período analisado - impeachment e governo Temer). A segunda, com 29 análises, foi celebridade.

Numa meta-análise de nosso trabalho, e considerando o acervo do Grislab como um banco de dados, temos retomado as análises publicadas para investigar a natureza e as ênfases ressaltadas pelos acontecimentos que foram ali registrados. Neste texto, olhamos para os 29 acontecimentos relativos a celebridades que se destacaram nesses quatros anos: por que "celebridades" ganham tanta proeminência, e o que esta proeminência diz de nós, sociedade contemporânea? Quem são essas celebridades, e que tipo de ação empreenderam, que fez notícia?

No meio acadêmico (onde elas também existem), celebridades provocam um movimento contraditório. Por um lado, e enquanto fenômeno social e cultural, se tornam objeto de estudo e inauguram um novo campo de pesquisa $^{3}$. Por outro, são vistas por muitos como um objeto pouco importante, senão totalmente irrelevante, sendo o fenômeno da celebridade interpretado como superficial e banal.

Ora, não é irrelevante um fenômeno que envolve, de maneiras diferentes, milhões de pessoas; não é superficial uma força que interfere na vida e na ação de amplas coletividades. Alcançar uma compreensão mais aprofundada do seu significado e implicações é um desafio e uma responsabilidade colocados para nós, pesquisadores/as da comunicação - porque, em grande medida, o fenômeno, em sua versão contemporânea, está calcado nas possibilidades de criação, divulgação e visibilidade proporcionadas pelas tecnologias comunicacionais.

Partimos do pressuposto de que as figuras de destaque em uma sociedade sinalizam inquietações, anseios e valores de uma sociedade. Assim, nosso objetivo, ao olhar para os acontecimentos que envolveram celebridades registrados por nosso laboratório, é perceber, através daquilo que os acontecimentos dizem, flashes de nossa vida social.

Sem pretender desenvolver, neste espaço, uma revisão completa da literatura que trata 
da temática, discutimos, inicialmente, o conceito de celebridade, evidenciando a relação entre celebridades, valores e acontecimentos - central na construção de nossa perspectiva. Em seguida, dedicamo-nos a olhar para os 29 acontecimentos analisados em nosso laboratório protagonizados por celebridades, reduzindo o corpus para 18 casos, como será explicado adiante. Ao final, em uma breve conclusão, analisamos os valores que sustentam as ações dessas celebridades e que revelam traços da sociedade em que se inscrevem.

\section{Celebridades: um fenômeno de nosso tempo?}

Se é verdade que o surgimento de múltiplas celebridades é marca de nosso tempo, é preciso lembrar também que a existência de pessoas célebres e cultuadas existiu desde o início da história, e o fenômeno da fama e da celebrização de fatos e personagens não é uma prerrogativa de nossa era. Diferentes estudiosos buscaram discutir a construção histórica da fama. Segundo Braudy (2007, p. 182, tradução nossa), "[...] o desejo de reconhecimento é uma parte da natureza humana, especialmente sensível tanto às estruturas sociais como ao modo e à extensão das comunicações em uma sociedade". Em sua reflexão sobre a história do fenômeno, o autor situa seus primórdios na trajetória de Alexandre, o Grande, rei da Macedônia, considerado a primeira pessoa famosa do mundo antigo.
Minois (2012) lembra, antes da Idade Média, da existência de certas celebridades oriundas das camadas populares - os santos. Artistas, escritores, intelectuais seriam alçados à fama com o Renascimento.

Entretanto, é na Modernidade que vários pesquisadores (MARSHALL, 2006; MORIN, 1989; ROJEK, 2008; GAMSON, 1994) localizam a emergência do fenômeno de celebrização que persiste (e se transforma) na sociedade contemporânea. A urbanização, a industrialização, o individualismo, entre outros fatores, são apontados como fatores importantes na construção da celebridade moderna. Mais recentemente, estudiosos discutem as transformações que as redes digitais vêm promovendo no fenômeno da fama. Marshall (2019) atenta para as mudanças no cenário cultural contemporâneo e suas implicações para o nexo entre fama e política. Marwick (2016) discute a emergência do que nomeia microcelebridades nas redes sociais digitais.

O que é possível apreender da história dos processos de celebrização, assim, é que produzir e reverenciar figuras de referência (grandes líderes, heróis, mártires, figuras do mal) faz parte da natureza e da dinâmica organizativa das coletividades humanas. No entanto, é interessante registrar que tais figuras devem ser compreendidas não (apenas) por características intrínsecas de alguns indivíduos, 
o que significaria uma personalização do fenômeno, ou através de uma explicação psico-social (necessidade e busca de um líder ${ }^{4}$ ), mas, sobretudo, pelo viés social - por sua ligação às tendências e às configurações de poder nas sociedades nas quais se destacam. O fenômeno, portanto, é universal, mas as celebridades são históricas e refletem o contexto em que surgem.

É por isso que estudar as celebridades nos fala de algo que as ultrapassa e é constituinte de cada momento social. É também este traço que nos direciona para as particularidades que conformam o próprio conceito de celebridade na contemporaneidade.

Existem controvérsias em relação à presença e ao estudo das celebridades - na academia e no senso comum. Para alguns, a palavra é revestida de um sentido depreciativo: celebridade é um termo que se aplica a pessoas dotadas de uma fama passageira, conquistada de forma oportunista e por razões pouco consistentes, distinguindo-se, inclusive, daquelas "justificadamente famosas", como um grande artista, uma grande personalidade no terreno da política ou da religião. Podemos lembrar aqui, por exemplo, a discussão pioneira de
Boorstin (1992), que cunhou o conceito de pseudoacontecimento para pensar o cenário criado pelas indústrias culturais. Em tal perspectiva, a celebridade é um pseudoacontecimento humano - ela é desprovida de qualidades, construída com o objetivo de ganhar visibilidade e gerar lucro.

Nas últimas décadas, entretanto, vem crescendo o número de pesquisadores/as em diferentes países que se dedicam a estudar o fenômeno da fama. Em A Companion to Celebrity (2016), encontramos um bom panorama de pesquisas que reconhecem o significado das celebridades em nossa cultura e sinalizam para a maturação de um campo de estudo dentro da academia - os celebrity studies (MARSHALL; REDMOND, 2016. Nossa perspectiva se situa ao lado desses esforços na tentativa de compreender a cultura das celebridades na contemporaneidade.

Para tanto, adotamos um conceito mais abrangente de celebridade (que não a reduz a um pseudoacontecimento): entendemos, de forma quase literal, que "celebridades" são pessoas que - por razões diferenciadas - se tornam amplamente conhecidas e, para além disso, admiradas (ou detestadas), provocam 
sentimentos de adesão e/ou repulsa, são tomadas como modelos (ou contra-modelos), suscitam formas distintas de celebração. Usamos o termo praticamente como sinônimo de "famosos", "pessoas públicas de referência", destacando três sentidos enfeixados pelo conceito: conhecimento, reconhecimento, culto. Celebridade qualifica alguém "[...] que se torna conhecido por muitas pessoas, reconhecido por aquilo que é ou faz, cultuado enquanto uma certa excepcionalidade digna de admiração e reverência" (FRANÇA, 2014, p. 19).

Tais sentidos marcam a construção de inúmeras personalidades ao longo da história, mas há alguns aspectos que especificam bem a celebridade contemporânea, quais sejam,

[...] o meio ou dispositivo através do qual a fama se espraia e se estabelece (que é a mídia); um caráter talvez mais epidérmico ou circunstancial (o status de celebridade não traz nenhuma garantia de consistência e durabilidade - e é quase o contrário, pois em torno do rótulo paira uma suspeita de volatilidade); uma ampliação das condições e perfis suscetíveis de se tornar celebridade. (FRANÇA, 2014, p. 20)

Isto dito, fica evidente que existem diferentes tipos de celebridade, que elas o são em graus diferenciados e por razões distintas e, sobretudo, não devem ser submetidas a uma medida comum. Grosso modo, celebridades se constituem a partir de três fundamentos: as qualidades que ostentam, o lugar institucional que ocupam, sua presença/participação em algum acontecimento de destaque ${ }^{5}$. Tais aspectos são geradores de visibilidade; a visibilidade, se bem aproveitada, proporciona a fama, desperta sentimentos de adesão ou rejeição.

\section{Celebridades podem surgir em pratica-} mente todos os campos da vida social - da política à religião, das artes ao esporte, com especial destaque para o campo midiático e vêm suscitando o interesse de inúmeros/

5 Tais fundamentos podem ser associados a uma tipologia bastante conhecida pelos estudiosos de celebridade construída por Rojek (2008). 0 autor aponta três tipos que revelam como alguém se torna uma celebridade: "A celebridade conferida tem relação com linhagem: o status decorre da linha de sangue. [...] Em contraste, a celebridade adquirida deriva de realizações do indivíduo observadas em competições abertas" (ROJEK, 2008, p. 20, grifo do autor). De acordo com Rojek, as celebridades que apresentam esse segundo status são reconhecidas na esfera pública "como indivíduos que possuem raros talentos ou habilidades" (ROJEK, 2008, p. 20). Entretanto, o pesquisador ressalta que "a celebridade adquirida não é exclusivamente uma questão de talento ou habilidade especial. Em alguns casos, ela resulta da concentrada representação de um indivíduo como digno de nota ou excepcional por intermediários culturais. Quando é assim, é celebridade atribuída" (ROJEK, 2008, p. 20, grifo do autor). 
as pesquisadores/as. ${ }^{6}$ Em linhas gerais, os estudos sobre a temática destacam alguns traços que marcam as celebridades de nosso tempo: a diversidade de origem e inserção, a proliferação (a existência em grande número), a duração passageira (o caráter descartável de muitas delas), o uso e presença em diferentes mídias - mídias de massa e redes digitais.

Não podendo nos ocupar, nos limites deste texto, desses inúmeros aspectos (e inclusive da distinção entre celebridades de maior ou menor consistência), nosso objetivo, como dissemos no início, é identificar aquilo que elas sinalizam: tomando-as como "faróis", perceber de onde elas vêm e o que elas apontam. É neste sentido que destacamos a conexão entre celebridades e valores, como discutiremos a seguir.

\section{Celebridades e valores}

Celebridades sinalizam valores; elas agregam preocupações, tendências, aspirações que dizem dos públicos que as admiram. Elas exibem traços e características apreciados em uma sociedade em certo momento o que pode ser percebido a partir das ações que as celebridades realizam no contexto social. Essa abordagem dos valores a partir da ação é construída por Joas (2000). O sociólogo pragmatista propõe que é na ação dos sujeitos que devemos investigar a emergência dos valores. Assim, é na experiência e na performance das celebridades que encontramos aquilo é valorizado (ou repudiado) em uma sociedade. Ou seja, é na experiência dos famosos que podemos apreender os valores sociais que eles sinalizam.

Seguindo essa perspectiva, como compreender os valores? O conceito de valores, e, sobretudo, quando falamos de celebridades, traz ambiguidades. Por um lado, constituir celebridade (fazer com que alguém se torne célebre) significa investir alguém de valor - é um processo de valorização. Por outro lado, uma pessoa se torna célebre exatamente porque porta em si/representa/espelha algo que uma comunidade valoriza, um valor.

Nathalie Heinich (2017), em uma obra em que discute a profusão de julgamentos de valor e do confronto de opiniões em nossa atualidade cotidiana, nos ajuda a elucidar esta questão. Inicialmente, ela nos apresenta três 
formas de atribuição de valor, três categorias de "marcadores", a saber: a medida, o apego e ojulgamento.

Podemos indicar o valor de algo (objeto, pessoa) através da medida, um marcador quantitativo e que pode se efetivar a partir de diferentes instrumentos, tais como preço, sistemas classificatórios, prêmios. O preço de uma obra de Da Vinci nos dá uma clara ideia de seu valor; publicar numa revista A-1 no Qualis Capes é muito mais significativo que uma B3 (nossa publicação "vale" muito mais no nosso lattes); receber um Prêmio Pulitzer é certamente uma grande honraria.

Outra marcador de valor é o apego (a ligação afetiva), que se revela por gestos, atitudes, condutas, tais como aplausos, reverências, adesão, uso de marcadores. Trata-se de uma relação estabelecida com o objeto, pessoa ou situação valorizadas atravessada por sentimentos e emoções fortes, adesões apaixonadas, sentimento de identificação O prestígio do papa, por exemplo, pode ser apreendido pela aglomeração e atitude dos fiéis na praça do Vaticano nos momentos em que ele aparece para abençoar a multidão; o valor de tal ou tal celebridade se revela através do surgimento de fã-clubes, do esforço que seus seguidores fazem para assistir a seu show ou recepcioná-lo num aeroporto. Faixas e bottons pedindo a liberdade de Lula nos indicam o apego que parte considerável de brasileiros confere ao ex-presidente, e assim por diante.

O julgamento, por sua vez, passa essencialmente pelo uso das palavras e se expressa pela noção de opinião; apoia-se em critérios ou argumentos, motiva e orienta ações. A eleição de um político pelo voto é resultado do julgamento e aprovação por parte de eleitores; o vencedor de um concurso, como o Master Chef, é a premiação de alguém atribuída por um júri, conforme determinados critérios estabelecidos.

Pensando nas celebridades como algo revestido de valor, podemos nos perguntar quais marcadores indicam o quanto ela é valorizada - e as três formas de atribuição de valor podem se verificar, ou uma delas se mostrar predominante e decisiva para a celebrização de uma pessoa. A medida se verifica, por exemplo, no preço cobrado pela celebridade para uma apresentação (quanto custa uma palestra do padre Fábio de Melo?), no preço do passe de um jogador, na quantidade de seguidores nas redes sociais (este índice é decisivo inclusive para o patrocínio por parte de marcas - veja-se o caso das blogueiras de moda).

O julgamento aparece na apreciação das qualidades e atitudes do célebre; um fato 
significativo na eleição presidencial de 2018, no Brasil, foram as fortes reações (de aprovação ou repúdio) suscitadas pelo posicionamento de celebridades 7 . Na Copa de 2014, atitudes do jogador David Luiz foram apreciadas como marca de "bom moço".

Sem dúvida, porém, o marcador decisivo no caso das celebridades é o apego, a ligação afetiva. Os fãs se deslocam grandes distâncias para ver seu ídolo, fazem filas para comprar ingressos de shows, colecionam fotos e informações. É observando a emoção que despertam e os sentimentos de que são revestidos que podemos avaliar a força e o grau de celebrização dos famosos.

Também nos sentidos da palavra "valor", Heinich nos traz contribuição significativa. Para a autora,

Poucos termos são tão polissêmicos como este de "valor": seu espectro semântico vai da moral às finanças, da filosofia às matemáticas, da música à pintura e à linguística, enquanto sua extensão cronológica vai da bravura do guerreiro antigo à técnica informática... Para além da definição prudentemente tautológica do dicionário ("aquilo que vale uma coisa"), pode-se, em todo caso, destacar três significações principais nos usos atuais desse termo tão familiar. (HEINICH, 2017, p. 133)

São elas o valor-grandeza, o valor-objeto e o valor-princípio. Na primeira significação, valor-grandeza,

[...] o valor equivale à grandeza intrínseca de um objeto qualquer, motivando sua apreciação positiva: em função dos objetos aos quais se aplica, o termo pode ser sinônimo de "importância", de "mérito", de "qualidade", de "quantidade", de "virtude" (no sentido antigo de virtus), ou mesmo de "preço" em sentido figurado. (p. 133-134)

Este é o sentido mais corriqueiro, e é como valor-grandeza que indagamos: "qual o valor deste relógio?”, “Quanto está valendo o dólar hoje?" Ou ainda: "Este é um equipamento de última geração, de excelente qualidade".

Na segunda significação, valor-objeto, "[...]um valor é um objeto creditado de uma apreciação positiva, quer dizer, um objeto considerado como dotado de valor no primeiro sentido do termo" (p. 134), referindo-se tanto a objetos concretos (uma casa de grande valor ou um vaso que pertenceu a um antepassado e tem grande valor simbólico para a família) como abstratos - a família como valor supremo, por exemplo. 
A terceira significação, valor-princípio, por sua vez, se refere

[...]não a uma apreciação, como na primeira, nem a um objeto concreto ou abstrato, como na segunda, mas ao princípio que sustenta uma avaliação: por exemplo, dizer que "esse filme é muito bonito" implica que, para o locutor em questão, no contexto da enunciação em questão e a propósito do objeto em questão, a "beleza" é um valor. (p. 135, grifo nosso).

Para nos referirmos a uma celebridade, podemos utilizar o termo nas duas primeiras significações. Utilizamos o valor-grandeza quando nos referimos à qualidade técnica de um jogador, à voz de um tenor, à performance dramática de tal artista.

Por outro lado, é a segunda significação, valor-objeto, que sustenta o julgamento (uma das três formas de atribuição de valor, conforme falado anteriormente) de uma celebridade, ou seja - a avaliação de por que tal figura é valorizada. Messi foi considerado um dos melhores jogadores do mundo; Chico Buarque é um dos maiores compositores da música popular brasileira; Janaína Pascoal teve um grande potencial de votos. Usamos este segundo sentido para qualificar e categorizar as celebridades, e ele nos indica um caminho promissor de análise: em que medida uma celebridade tem valor, calcado em que atributo ou situação. Dito de outra maneira, que valor-grandeza tal indivíduo ostenta que lhe confere o status de "indivíduo de valor" (a destreza de Messi torna-o um jogador famoso - e um dos mais bem pagos na atualidade).

Mas é sobretudo o terceiro sentido, de valor-princípio, que nos interessa na presente reflexão. Mais do que estudar as celebridades em si, em seu valor intrínseco, nos interessa indagar o que elas representam; que valores estão em jogo (se mostram atuantes) quando se dá destaque, por exemplo, a um bom lutador (Anderson Silva, vencedor do UFC) ou a uma pessoa que vive uma vida de desprendimento e cuidado do próximo (Madre Teresa de Calcutá). Lutar bem, ou viver uma vida de desprendimento e doação seriam, em qualquer tempo e lugar, alvos de destaque e apreciação positiva? É por este caminho - o que nos dizem as características e atitudes de uma celebridade - que seu estudo ganha relevância. Ao se tornar célebre por ostentar algo, elas sinalizam e representam algo que uma sociedade, em tal momento, valoriza ou repudia.

Como já ressaltado acima, na perspectiva pragmatista que nos anima, valores se manifestam em nossas ações - orientam nossa prática. Assim, na análise que nos propomos a fazer dos acontecimentos que envolveram celebridades, interessa identificar que tipo de ação foi protagonizada por elas, como elas se posicionaram, qual foi a reação 
do público. Tais elementos nos darão pistas sobre os valores-princípio que estão atuando em tais acontecimentos.

\section{Celebridades e acontecimentos}

Celebridades podem surgir de acontecimentos, assim como, com frequência, e de maneira mais ou menos estratégica, elas os provocam (LANA; SIMÕES, 2012). Além disso, algumas celebridades, pelo lugar ocupado na sociedade e pela força de adesão junto a seus públicos, podem ser pensadas como acontecimento (SIMÕEs, 2012a).

Acontecimentos são ocorrências que quebram a normalidade da vida social; são emergências que rompem com a continuidade da experiência e afetam a vida dos sujeitos. Esta é uma característica central em nossa compreensão dos acontecimentos: a sua passibilidade (QUÉRÉ, 2005, 2012). Os acontecimentos têm um poder de afetar a experiência das pessoas, desencadeando (re)ações em determinado quadro espaço-temporal. Segundo Quéré (2000, p. 11), o acontecimento “[...] dura o tempo que dura a atualização de seu potencial de criação de intrigas, de revelação de possíveis ou de modificação de situações, assim como de afetação [...] daqueles a quem ele acontece". Outra característica marcante desta perspectiva é o poder hermenêutico do acontecimento: ele é "fonte do sentido, fonte de compreensão" (p. 35), tem um "poder de revelação ou de descoberta" (p. 62). Ou seja, o acontecimento suscita sentidos, provoca falas, abre perspectivas inesperadas que colaboram na compreensão do contexto social mais amplo em que ele emerge.

Assim, ao observar e registrar acontecimentos marcantes em nossa sociedade através de nosso laboratório, quando celebridades se tornam a segunda categoria de maior destaque, é interessante perguntar de onde elas vêm e que tipo de ação suscitou interesse e fez falar. Conforme registrado inicialmente, nas 253 análises realizadas pelo Grislab em quatro anos, 29 referiam-se a acontecimentos protagonizados por celebridades, totalizando 38 figuras públicas de destaque ${ }^{8}$

8 1) Ana Hickmann, 2) Alexander de Almeida (rei do camarote), 3) Bruno (goleiro), 4) Chico Buarque, 5) Roberto Carlos, 6) Cristiano Araújo, 7) David Luiz, 8) Domingos Montagner 9) Fátima Bernardes, 10) William Bonner, 11) Fábio Assunção, 12) Fernanda Montenegro, 13) Nathália Timberg, 14) Gisele Bündchen, 15) Gretchen, 16) Jair Bolsonaro, 17) Joelma, 18) Chimbinha, 19) Justin Bieber, 20) Leonardo DiCaprio, 21) Levy Fidelix, 22) Mallu Magalhães, 23) MC Biel, 24) Mohamed Ali, 25) Mateus Solano, 26) Robin Williams, 27) Rodrigo Hilbert, 28) Simone, 29) Stênio Garcia, 30) Taylor Swift, 31) Kanye West, 32) Tony Ramos, 33) Angélica, 34) Trump, 35) Datena, 36) Victor, 37) José Mayer, 38) Marcos Harter. 
(sendo que três ${ }^{9}$ delas se repetiram em mais de um acontecimento).

Naturalmente, trata-se de um pequeno extrato de realidade; nosso universo de análise (as celebridades que foram acontecimento em nosso site) traz os limites de todo recorte, que são os critérios e princípios endossados por quem faz a seleçãa $0^{10}$. Não pretendemos, portanto, generalizar esse corpus como uma tradução fiel dos acontecimentos que envolveram celebridades nos últimos anos e que tiveram ampla repercussão na sociedade.
Certamente, alguns acontecimentos com celebridades relevantes no período não foram registrados por nossa coleta; igualmente, podemos ter dado mais destaque a algum acontecimento que o merecido sob outros olhares. Portanto, e como dissemos antes, a análise desse corpus tanto nos fornece flashes da realidade (daquilo e daqueles que, num certo período, se destacaram) como constitui uma meta-análise de nosso próprio trabalho no laboratório (o que nos chamou a atenção e o que selecionamos enquanto acontecimento de destaque).

Tabela 1-Celebridades, Acontecimentos, Campos de Atuação

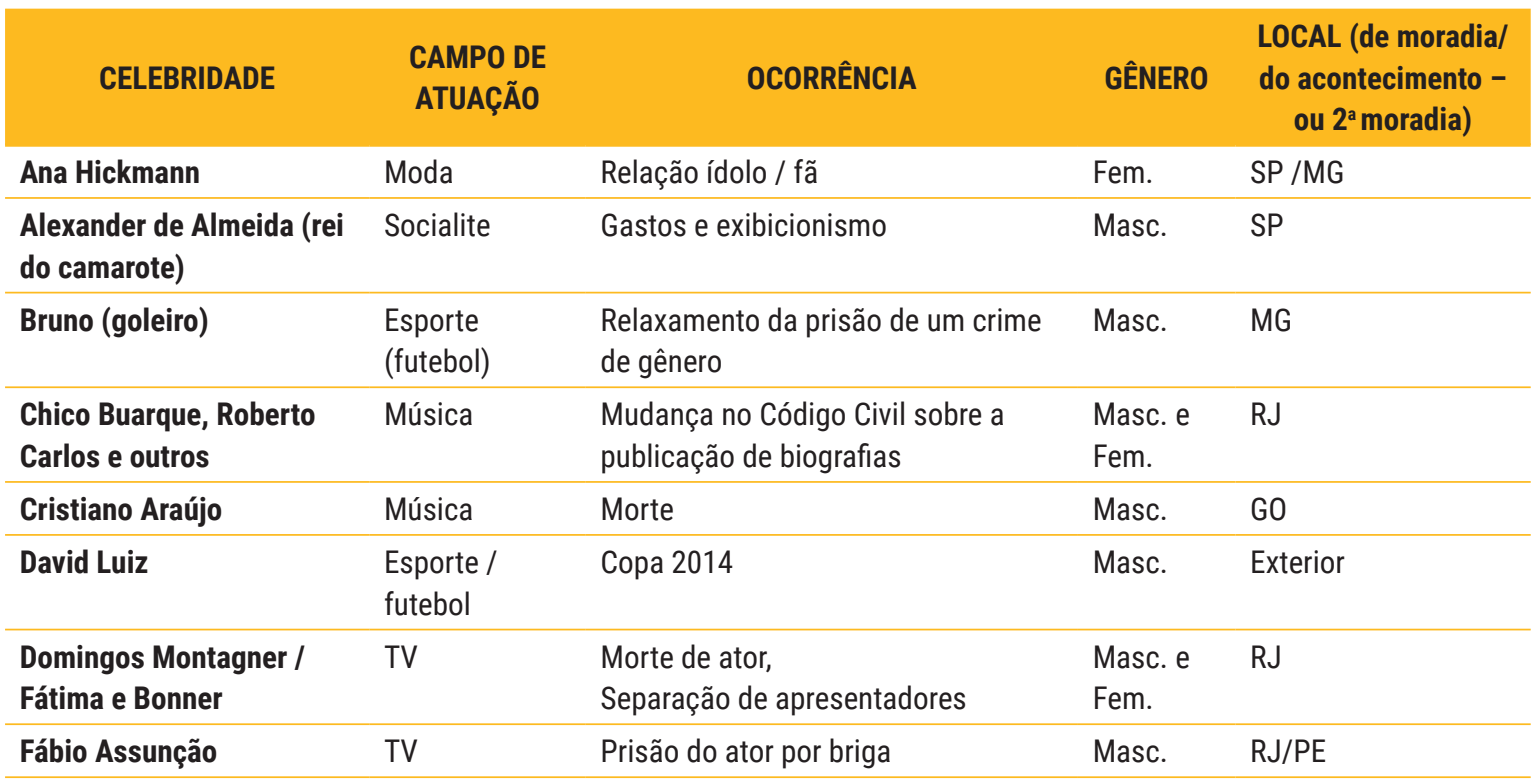

9 Fátima Bernardes, Mc Biel e Roberto Carlos.

10 Os acontecimentos analisados e publicados no Grislab são selecionados por comissão editorial (composta por dez pessoas) em reunião de pauta, e o critério utilizado é repercussão e relevância social do acontecimento. Normalmente, são publicados dois acontecimentos por semana; em alguns momentos, pode-se publicar três. 


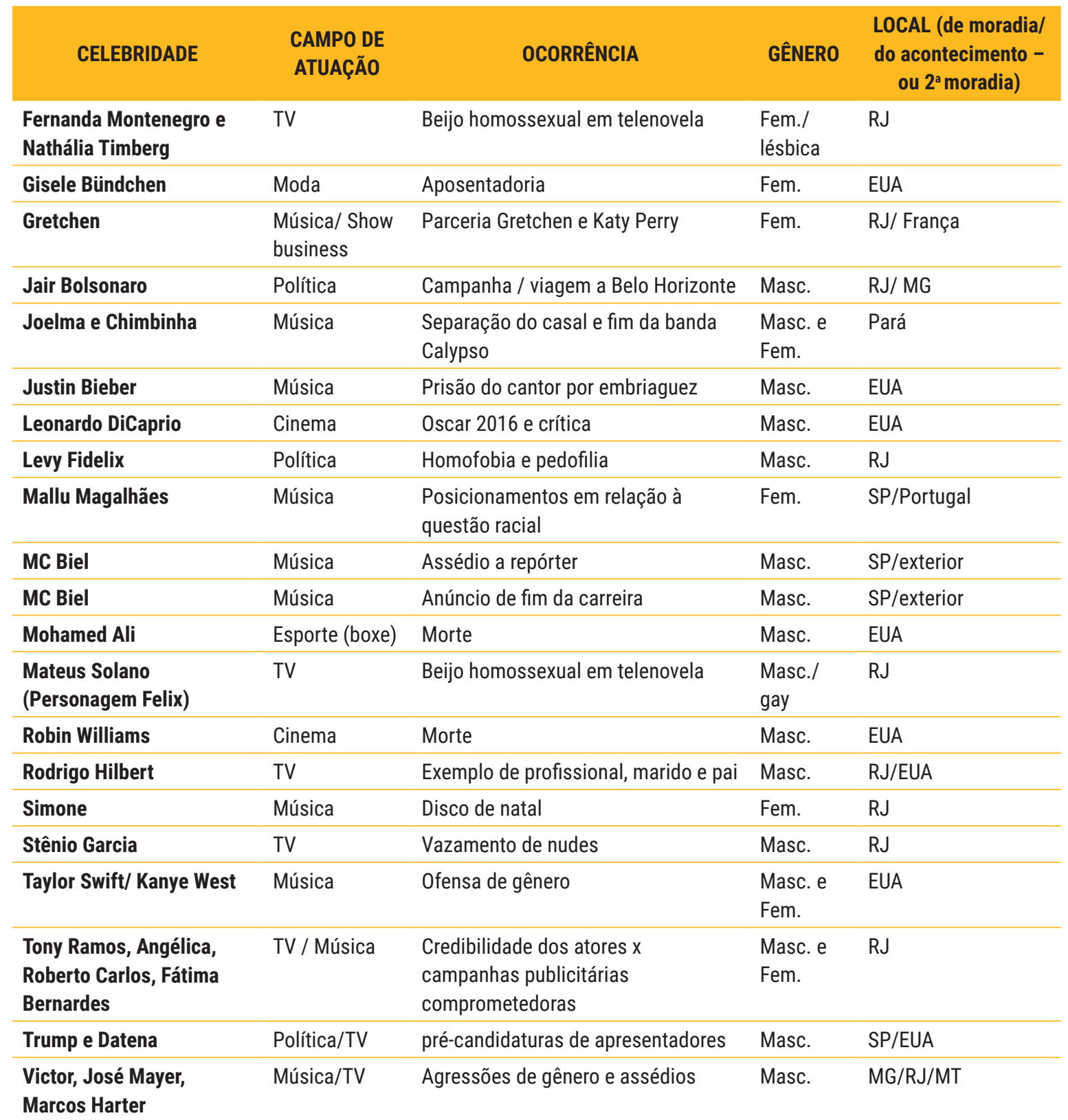

Nossa primeira identificação diz respeito à área de atuação do/as famosos: dentre os 38 nomeados, 14 estão inscritos predominantemente na TV; 13 no campo musical; dois no cinema; três no esporte (sendo dois no futebol); três na política; dois na moda e um nas colunas sociais. Chama a atenção a absoluta predominância, neste recorte, do campo midiático: $29 \mathrm{em} \mathrm{TV}$, música e cinema (sendo 27 em Tv e música), o que indica a incidência desse perfil (artistas) na composição da galeria dos célebres de nosso país e tempo.

Quanto ao conteúdo do acontecimento, numa primeira aproximação podemos traçar o seguinte mapa: sete sobre aspectos da 
carreira profissional (fim de carreira, atuação em comerciais); dois sobre embates vida profissional/vida privada (biografia; ataque de fã); 10 sobre aspectos da vida pessoal (brigas, separações, incluindo quatro mortes); oito sobre questões de gênero (sendo cinco sobre violência, dois sobre beijo gay, um sobre homem "correto"); um sobre questão racial; três sobre política (dois sobre campanha eleitoral; um de crítica). Consideramos que é normal e esperado tratar publicamente de aspectos ligados ao desempenho profissional de figuras públicas, posto que este constitui justamente a atividade que lhes confere proeminência. O destaque, porém, de questões ligadas à vida pessoal não deveria ser natural; da mesma maneira, a incidência de questões de gênero é sintoma de algo que se passa na vida social.

Observando o recorte do ponto de vista de gênero, constatamos que, dentre as 29 análises, 17 foram protagonizadas por pessoas do sexo masculino, cinco do sexo feminino, cinco falavam de pessoas dos dois sexos, duas eram personagens homossexuais de telenovela (lésbica e gay). É bem verdade, como veremos adiante, que em muitas análises o acontecimento tratava de machismo e homofobia por parte de homens. De toda maneira, também em nosso site (um laboratório que combate o machismo e o patriarcalismo), constatamos o grande protagonismo masculino: tanto são os homens que mais estão à frente dos acontecimentos que ganham destaque como nós, ao selecionarmos os acontecimentos, também reproduzimos (sem nos darmos conta) esse desequilíbrio de gênero na cena social.

As celebridades brasileiras aqui registradas moram, em sua grande maioria, no Rio de Janeiro - 18 dentre elas (duas com segunda residência no exterior); cinco moram em São Paulo (duas com segunda residência no exterior); sete de outros estados; duas no exterior (EUA e Europa). E seis são estrangeiras, todas dos Estados Unidos. Ou seja: os "célebres" não estão distribuídos geograficamente de forma homogênea no país, mas se concentram predominantemente no eixo Rio-São Paulo, onde também estão situados os principais veículos de comunicação do país.

Numa síntese provisória, podemos observar que os acontecimentos que fizeram falar, observados por nosso laboratório, bem como o perfil das celebridades, permanecem dentro de um enquadramento hegemônico: maioria de homens; localização geográfica no Rio e, em menor grau, em São Paulo (quando não exterior - e EUA); um forte acento sobre aspectos da vida pessoal e questões de gênero; predominância absoluta (quanto ao perfil das celebridades) da inserção no meio artístico e midiático. São 
dados descritivos, mas observá-los nos diz algo sobre nossa realidade.

Partindo desse mapa geral, fizemos um segundo recorte, em busca dos valores-princípio que sustentam a ação das celebridades nos acontecimentos analisados.

\section{Celebridades, acontecimentos e valores-princípio}

A natureza dos acontecimentos e o tipo de reação suscitada nos indicam quais valores foram acionados e sustentam as ações das celebridades e/ou do público. Para fazer essa identificação, trabalhamos com um corpus menor, fazendo um recorte nas 29 análises citadas. Para isso, privilegiamos duas categorias de ocorrência - aquelas relacionadas à vida privada e as que tratam de gênero (que, de certa maneira, também seriam aspectos relacionadas à vida privada das personalidades públicas). Esta escolha se justificou pela maior incidência dessas duas categorias, mas também porque este aspecto (vida privada) não é - ou não seria - diretamente ligado ao valor-grandeza da celebridade, à qualidade que teria contribuído para sua projeção. Vale destacar também que a sustentação do interesse por sua vida privada é um dos fatores que ajuda a caracterizar uma celebridade, conforme discutido por Turner (2004). Nesse novo recorte, temos um corpus de 18 casos, discutidos a seguir conforme algumas categorias de ocorrência.

A ocorrência mais presente foi a morte - de Domingos Montagner, Cristiano Araújo, Mohamed Ali e Robin Williams. O traço laico da cultura ocidental prevalece nas reações frente à morte: ela é vista com pesar e lamentada, afetando os sujeitos de diferentes maneiras. Como destaca Rodrigues (2006, p. 40), “[...] as emoções a sentir e a expressar — tristeza, indiferença, alegria — não são absolutamente questões de decisão individual", mas dependem "do tipo de morte [...], da condição do morto [...], da posição social do sobrevivente e de sua relação com o desaparecido". No caso de mortes trágicas e precoces, a morte evoca o valor da juventude e o pesar pela interrupção de um futuro promissor. Ou seja, a morte é lamentada porque atenta contra a vida que poderia continuar. Por isso, ela comove, suscita proximidade, mobiliza as pessoas, que se sentem plenamente afetadas tanto pela compaixão com o falecido como por serem lembradas da imprevisibilidade e da irredutibilidade da morte de todos nós. Neste sentido, e frente à morte, nos igualamos todos.

A morte de Mohamed Ali e Robin Williams acontece numa fase de envelhecimento; a leitura se volta mais para a trajetória precedente, valorizando suas dificuldades e realizações. Também se destaca o sofrimento com 
a doença (Doença de Alzheimer, no caso de Mohamed Ali; Mal de Parkinson e depressão, no caso de Williams) e a luta para enfrentá-la. A ideia de morte não se sustenta exatamente em um valor-princípio - ela atenta contra um grande valor, que é a vida. ${ }^{11}$

Outra ocorrência foi a separação de casais: Fátima Bernardes e William Bonner, Joelma e Chimbinha. Esses dois acontecimentos se deram em contextos diferentes: a separação de Fátima e Bonner causou grande surpresa, pois eles sempre sustentaram a imagem de casal perfeito. A separação do outro casal, por sua vez, ocorreu a partir de uma justificativa, que foi a traição de Chimbinha. Os debates de um e outro caso suscitaram um valor comum que é a indissolubilidade do casamento e o sonho da família idílica. Tal valor integra o ideal de amor romântico, em que se destaca "[...] a possibilidade de se estabelecer um vínculo emocional durável com o outro, tendo-se como base as qualidades intrínsecas desse próprio vínculo" (GIDDENS, 1993, p. 10). No primeiro caso, os protagonistas, por muitos anos, alimentaram o modelo da família ideal: mulher e homem bem-sucedidos profissionalmente, bonitos, com três filhos lindos e saudáveis. Assim, a separação significou muito mais do que uma separação - ela comprometeu a sustentação de um modelo de referência, gerando protestos e, sobretudo, lamentações.

No segundo caso, a traição de Chimbinha justificou a separação: temos aí o valor da reparação, ou mesmo da vingança (um malfeito pede uma resposta, sob pena de diminuir o ofendido). Porém, o valor da indissolubilidade do casamento também se fez presente, em comentários que estimulavam o perdão por parte de Joelma.

Tivemos dois casos de prisão - de Fábio Assunção e Justin Bieber. A razão foi praticamente a mesma - embriaguez, desacato -, e o valor-princípio que orienta os comentários em torno desse acontecimento é de justiça para todos. Entendemos justiça como um valor ligado a questões relativas à "[...] maneira como os indivíduos devem tratar uns aos outros. Elas também dizem respeito a como a lei deve ser e como a sociedade deve se organizar" (SANDEL, 2009, p. 14). Porém, não se trata de um valor inconteste; nas duas ocorrências, a atitude das celebridades revelou um sentimento de estar acima da lei - considerando-se seres especiais, mereceriam um tratamento igualmente especial. Fábio Assunção disse que 
daria um autógrafo para o policial e seria liberado; ações inconsequentes de Justin Bieber (como cuspir nas fãs) também indicam o descompromisso com as normas.

Além disso, a controvérsia dos públicos atesta que não apenas elas, mas também os fãs ardorosos concordam com esse "valor especial" de uma grande celebridade; no caso de Justin Bieber, os beliebers defenderam veementemente o seu ídolo, entrando em choque com haters (pessoas cuja motivação de vida na web está na manifestação de ódio a figuras públicas), que chegaram a criar até uma petição on-line para que ele fosse deportado dos EUA. Quanto a Fábio Assunção, com um histórico de dependência química e, além de tudo, um ator já mais velho e com a carreira em declínio (ao contrário de Bieber), mais do que defensores ou críticos, houve chacota e, em contraposição, pessoas que se solidarizaram com sua fraqueza e se sensibilizaram com seu pedido de desculpas (sua atitude posterior de humildade).

Então, tivemos ações de desrespeito à lei que desvelam valores distintos: imunidade para seres especiais $X$ acirramento da cobrança, por eles se julgarem especiais; presença da compaixão e da valorização da humildade (reconhecimento da queda) X chacota com a desgraça alheia. Esses acontecimentos (e os valores revelados por eles) apontam para as dimensões divina e humana das celebridades, aspecto bem discutido na pioneira reflexão de Edgar Morin sobre os olimpianos (MORIN, 1997).

O vazamento de nudes de Stênio Garcia evoca uma série de valores bem contemporâneos: a busca de visibilidade e a ênfase da imagem, o culto do corpo, o exibicionismo e o voyeurismo, a sexualidade e a virilidade. Porém, tratando-se de um homem idoso, o acontecimento também evidenciou, pelo contraste, o culto da juventude (nudes de homens jovens circulam e despertam reações bem distintas) e o desrespeito com a velhice - o que revela a dificuldade da sociedade em lidar com o envelhecimento, como bem discute Norbert Elias (2001). O vazamento das imagens (se é que foi o que ocorreu) também revela uma disputa de valores em torno da fronteira público-privado e da invasão da intimidade (de famosos e de não-famosos). ${ }^{12}$

Já o caso do "rei do camarote" é interessante pelo efeito contraditório que provocou, revelando um alto grau de cinismo social. A projeção 
de Alexander de Almeida em uma matéria da revista Veja se propôs a reverberar a exibição e a ostentação de um novo rico, mostrando esse outro mundo, vivido por alguém que conseguiu ascender socialmente. Porém, a exibição caiu no ridículo - por seus gastos exagerados, mas também pela falta de carisma do exibicionista. Ele não era bonito, não era charmoso, não exibia nenhuma talento especial. Não era um jogador ou um artista de sucesso. Então, essa riqueza carecia de justificativa e se tornou caricatura. Se prestou ao deboche, ao revanchismo social, mostrando que a sociedade pode ser perversa para com aqueles que se destacam por razões e com características (valores) que ela não endossa.

Um conjunto de ocorrências do recorte diz respeito ao assédio e à violência contra a mulher, bem como às repercussões das ações das celebridades. A agressão física do cantor Victor à sua esposa acarretou seu desligamento do The Voice Kids e o cancelamento de shows já agendados. A denúncia de assédio envolvendo José Mayer trouxe o afastamento do ator do elenco de uma novela e a campanha \#mexeucomumamexeucomtodas. A agressão de Marcos Harter à sua namorada no Big Brother Brasil trouxe a sua expulsão do programa e seu indiciamento pela Polícia Civil do Rio de Janeiro. Nos três casos, houve uma grande mobilização de públicos variados: na defesa dos acusados, encontramos o machismo como um valor ainda muito atuante em nossa sociedade, assim como a ideia do homem poderoso e garanhão como modelo para muitos, reiterando o ideal de masculinidade ocidental (oliveira, 2004). Contudo, na crítica aos comportamentos machistas, apreendemos a igualdade e o respeito como valores-princípio, reivindicados nas lutas feministas nas últimas décadas e discutidos em vários trabalhos recentes (ARRUZZA, BHATTACHARYA; FRASER, 2019; BIROLLI, 2018; HOLLANDA, 2018; SARMENTO, 2018, entre outros). Esses acontecimentos exibem, assim, o embate de valores que se processa na própria sociedade contemporânea.

Na análise de MC Biel, também encontramos a denúncia do assédio e da violência simbólica contra a mulher - o que acabou impulsionando o anúncio do fim da carreira do cantor. A mesma questão aparece em uma ocorrência internacional. O rapper Kanye West cantou uma música ofensiva à também cantora Taylor Swift, que denunciou o machismo e a misoginia em seu discurso na entrega do Grammy. Outro caso relacionado à questão de gênero se refere ao relaxamento da prisão de Bruno Fernandes, condenado a 22 anos e três meses de prisão pela morte de Eliza Samúdio. O que chamou muito a atenção nesse caso foi a presença de fãs do ex-goleiro que tiraram selfies, além de manifestações de apoio a Bruno nas redes sociais, bem como propostas de 
emprego em clubes de futebol. É uma sociedade machista, que não reconhece o feminicídio como um crime que causa indignação social, que fomenta os traços de idolatria que Bruno ainda é capaz de sustentar. O que se coloca, assim, é a naturalização da violência contra a mulher, o que vem sendo discutido por vários pesquisadores/as (ANDRADE; MATOS, 2017; SARMENTO; MENDONÇA, 2017; SIMÕES; LIMA, 2018; MATOS, 2016).

Como um certo contraponto a tais casos mas que acaba reforçando os valores-princípio destacados - situamos o acontecimento em torno do "homão da porra" Rodrigo Hilbert. $\mathrm{O}$ apresentador vem suscitando a atenção pública a partir de ações tradicionalmente atribuídas ao universo feminino - cuidar dos filhos, cozinhar, cuidar da casa -, que falam de um outro lugar do homem (sensível, dedicado, afetuoso com a família) em nossa sociedade. A celebração em torno desse homem perfeito (bonito, bem-sucedido, com uma visão de mundo feminista) acaba por revelar o quanto a igualdade de gênero está longe de ser alcançada - já que esse mesmo homem é visto como ideal inalcançável.

As três últimas análises que integram o nosso recorte apontam para a homossexualidade e as relações LGBT. O carisma do personagem Félix, interpretado por Mateus Solano, na telenovela Amor à Vida, levou à torcida pelo beijo gay na tela da TV por parte de um público ampliado. A ocorrência foi muito comemorada tendo em vista o valor dessa representação para a luta LGBT - a luta por direitos, por respeito, por igualdade, mas também por diversidade, os valores-princípio que se revelam nesse acontecimento. Ao mesmo tempo, o beijo gerou críticas, mas o que se pode perceber nas reverberações desse acontecimento é como a representação LGBT entrou na pauta da sociedade, gerando disputas em torno da própria luta por essa representação na tela da $\mathrm{TV}$, como bem revelou a pesquisa realizada por Silva (2016). Neste sentido, a Rede Globo, conservadora em suas posições políticas, assume um lugar progressista.

A representação do beijo gay construída em Amor à Vida abriu caminho para a encenação de um beijo entre duas mulheres (vividas por Fernanda Montenegro e Nathália Timberg) já no primeiro capítulo de Babilônia. Houve apoio, mas também várias críticas; entre elas, em relação ao fato de serem duas mulheres idosas, representadas por atrizes consagradas na Tv brasileira. Aqui, novamente, emerge o valor da juventude e a desvalorização da velhice como marca também de nossa sociedade. Mas a trama ficcional envolvendo as duas persistiu até o fim.

Por fim, a polêmica declaração do presidenciável Levy Fidelix - em que relaciona 
a homossexualidade à violência, além de incitar a violência contra a população LGBT também dividiu opiniões. Enquanto grupos cobravam medidas judiciais contra o político, outros destacavam a liberdade de expressão como justificativa para a fala preconceituosa e homofóbica dessa figura pública. Esse acontecimento, ao lado das representações do beijo gay nas telenovelas, mostra como os valores-princípio do respeito e da igualdade de gênero estão em pauta - e em disputa - em nossa sociedade heteronormativa.

\section{Considerações finais}

O primeiro aspecto a se destacar diz respeito à importância das celebridades - em como os acontecimentos em torno delas despertam interesse e ocupam a pauta pública. Estamos registrando o óbvio - mas torna-se necessário "desnaturalizar" esse destaque que elas recebem, chamando a atenção para os perfis e os tipos de ação que ocupam as conversações. É relevante enfatizar quais acontecimentos são registrados e são acompanhados como significativos em nossa sociedade.

A propósito do tipo de conteúdo de grande parte desses acontecimentos relatados, como destaca Turner (2004), detalhes da vida privada das celebridades atraem a atenção de seus públicos, e a imprensa sensacionalista se esbalda com os escândalos em que elas se envolvem. O que vemos aqui é o interesse pelas relações pessoais, detalhes do cotidiano, ênfase no privado (num mesmo contexto em que o interesse pela política e pelos políticos decresce e é revestido de grande descrédito).

Embora não estejamos fazendo um estudo comparativo, podemos adiantar, de forma um pouco intuitiva, que, em outros momentos, os famosos já foram celebrados por suas "virtudes" (sua ação conforme os valores e as normas vigentes - por exemplo, seu heroísmo, seu desprendimento) e sancionados por suas transgressões (uso de drogas, vida considerada promíscua). Comportamentos considerados desviantes, inclusive, eram, tanto quanto possível, ocultados (como a homossexualidade).

Em nossos dias, os acontecimentos envolvendo as celebridades expõem rupturas e tensões, provocando reações polarizadas. No que diz respeito às questões de gênero e sexualidade, tanto assistimos a comportamentos e apoios ao modelo patriarcal e machista como críticas em direção a uma convivialidade marcada pela igualdade de gênero, pelo respeito às diferenças. Uma luta que se estende inclusive ao direito da representação da pluralidade.

Porém, outros valores se destacam: o culto da juventude e do amor à vida; a reverência à beleza - com a rejeição do feio e do velho; 
a apreciação do modelo do amor perfeito, porém, o direito à vingança; a solidariedade com o sofrimento, mas também um certo prazer com a desgraça alheia.

As celebridades que sobressaíram em nosso universo de análise vieram, em sua grande maioria, do campo midiático, notadamente TV e música, o que reforça a predominância do campo do entretenimento como referência central na sociedade. Esses são também terrenos onde a visibilidade alcança seu maior potencial e onde a aparência e a performance têm um papel preponderante - mais do que competências muito específicas. Confirma-se aí a importância da beleza, da corporeidade e da gestualidade, num contexto em que a visibilidade em si também se converteu em valor.

Porém, aquilo mesmo que é valorizado, neste contexto contemporâneo, se torna igualmente criticado. Há um prazer (novo?) em desvalorizar os famosos - questionar a presença de valores ou se contrapor àqueles exibidos pela celebridade. A admiração e o desprezo ombreiam, a solidariedade e a insensibilidade com o sofrimento alheio se confrontam, o humor sarcástico e a chacota (que sempre existiram) vêm à tona de forma mais despudorada.

Essas oscilações - as relações de amor e ódio, os impulsos de elevar e de destruir - se tornam mais facilitadas no terreno das celebridades em decorrência da forma de atribuição de valor predominante neste terreno, que é o apego, o revestimento de afetos, tal como discutido por Heinich (2017). Medidas supõem o uso de critérios; julgamentos se apoiam na construção de argumentos. Afetos são mais maleáveis, mais facilmente transportados.

Não estamos, com essas afirmativas, subestimando ou atribuindo aos afetos uma natureza epidérmica e pouco significativa. Eles são faróis de outros movimentos e indicadores de dinâmicas que ocorrem em camadas mais profundas. Os sentimentos em torno das celebridades mudam, variam - e o lugar e o papel delas também. Como dissemos em outro espaço (FRANÇA, 2010), elas são descartáveis: servem enquanto atendem àquilo que está valendo. Elas declinam e/ou são substituídas quando aquilo que representam deixa de ter importância.

Vivemos um momento de transição, com valores que oscilam, que estão sendo descartados, e com novos valores que surgem para se instalar. Celebridades nos ajudam a olhar para isso - desde que saibamos desviar os olhos delas em si mesmas e consigamos perceber aquilo que elas dão a ver. Ou seja: enfatizamos aqui que as celebridades são mais ou menos apreciadas em função de sua maior ou menor proximidade 
com os valores em alta. Elas espelham as contradições e embates de valores quando a sociedade enfrenta crises e fissuras, e é analisando suas atitudes, seus posicionamentos, bem como as reações que convocam que podemos apreender traços dessa mesma sociedade. Citando Inglis (2012, p. 26), "compreender o fenômeno celebridade se transforma, com variações de intensidade, em uma investigação sobre os melhores e piores valores da sociedade contemporânea ocidental". É esse tipo de compreensão que buscamos em nossas pesquisas sobre a cultura das celebridades.

\section{Referências}

ANDRADE, Luciana; MATOS, Marlise. A criminalização da violência contra as mulheres no Brasil: de "legítima defesa da honra" à violação dos direitos humanos. Revista Sociais e Humanas, v. 30, n. 2, p. 01-24, 2017.

ARRUZZA, Cinzia; BHATTACHARYA, Tithi; FRASER, Nancy. Feminismo para os $\mathbf{9 9} \%$. São Paulo: Boitempo, 2019.

BARBOSA, Marialva. A morte imaginada. In: ENCONTRO ANUAL DA COMPÓS, XIII., 2004, São Bernardo do Campo. Anais... São Bernardo do Campo: UMESP, 2004.

BIROLI, Flávia. Gênero e desigualdades: limites da democracia no Brasil. São Paulo: Boitempo, 2018.

BOORSTIN, Daniel. From hero to celebrity: the human pseudo-event. In: The image: a guide to pseudo-events in America. New York: Vintage, 1992. p. 45-76.
BRAUDY, Leo. The Frenzy of Renown: Fame and Its History. New York: Vintage Books, 1986.

CAMPANELLA, Bruno. O fã na cultura da divergência: Hierarquia e disputa em uma comunidade on-line. Contemporanea, Salvador, v. 10, n. 3, p. 474-489, 2012. Disponível em: $<$ https://portalseer.ufba.br/ index.php/contemporaneaposcom/article/ view/6435>. Acesso em: 15 jan. 2018.

DYER, Richard. Stars. New Edition. London: British Film Institute, 1998.

\section{ELIAS, Norbert. A solidão dos moribundos:} seguido de "Envelhecer e morrer". Rio de Janeiro: Jorge Zahar, 2001.

EPSTEIN, Rebecca. L. Sharon Stone in a Gab Turtleneck. In: REDMOND, S.; HOLMES, S.

(Ed.). Stardom and Celebrity. Los Angeles/ London/New Delhi/Singapore: Sage, 2007. p. 206-218.

FOFANA, Habibou. Norbert Zongo: das margens sociais ao coração do Estado: a constituição de um personagem público. In: FRANÇA, V.R.V.; OLIVEIRA, L. Acontecimento: Reverberações. Belo Horizonte: Autêntica, 2012. p. 173-191.

FRANCA, Vera R. V.. "Felicidade ao seu alcance": que felicidade, e ao alcance de quem, afinal?. In: FILHO, João Freire. (Org.). Ser feliz: reflexões sobre o imperativo da felicidade. 1ed.Rio de Janiro: FGV, 2010, v. , p. 213-226. FRANÇA, Vera R.V.; FREIRE FILHO, João; LANA, Lígia; SIMÕES, Paula G. Celebridades no século XXI: transformações no estatuto da fama. Porto Alegre: Sulina, 2014.

FRANÇA, Vera R.V.; SIMOES, Paula G. Celebridade: quando o privado atravessa o 
público (e vice-versa). In: CASTRO, Paulo César. (Org.). Dicotomia público/privado: estamos no caminho certo? Maceió, Alagoas: EDUFAL, 2015. p. 71-90.

GAMSON, Joshua. Claims to fame: celebrity in Contemporary America. Berkeley. Los Angeles: University of California Press, 1994.

\section{GIDDENS, Anthony. A transformação da}

intimidade. São Paulo: Unesp, 1993.

HEINICH, Natalie. Des valeurs: une approche sociologique. Paris: Gallimard, 2017.

HOLLANDA, Heloísa Buarque. Explosão

feminista: arte, cultura, política e universidade. São Paulo: Cia das Letras, 2018.

HOLMES, Su; REDMOND, Sean. A journal in Celebrity Studies. Celebrity Studies, v. 1, n. 1, p. 1-10, 2010.

JOAS, Hans. The genesis of values. Chicago: University of Chicago Press, 2000.

INGLIS, Fred. Breve história da celebridade. Rio de Janeiro: Versal Editores, 2012.

KAMRADT, João. Celebridades políticas e políticos celebridades: uma análise teórica do fenômeno. BIB, São Paulo, n. 88, 2019, p. 1-22.

KELLNER, Douglas. Celebrity diplomacy, spectacle and Barack Obama. Celebrity

Studies, v. 1, n. 1, p. 121-123, Mar. 2010, 121-123. Disponível em: $<$ https://www.tandfonline. com/doi/pdf/10.1080/193.923.90903519156>. Acesso em: 15. Jan. 2018.

LANA, Lígia. As contradições da fama da periferia: a celebrização de Tati QuebraBarraco. In: FRANÇA, Vera R.V.; FREIRE FILHO, João; LANA, Lígia.; SIMÕES, Paula G. Celebridades no século XXI: transformações no estatuto da fama. Porto Alegre: Sulina, 2014. p. 181-205.

Personagens públicas na mídia, personagens públicas em nós: experiências contemporâneas nas trajetórias de Gisele Bündchen e Luciana Gimenez. 2012. $284 \mathrm{f}$. Tese (Doutorado em Comunicação Social)Faculdade de Filosofia e Ciências Humanas, Universidade Federal de Minas Gerais, Belo Horizonte, 2012.

LANA, Lígia.; SIMÕES, Paula G. Duas vinculações possíveis entre personalidades e acontecimentos: diferentes modos de atuação na vida pública. In: FRANÇA, Vera R.V.; OLIVEIRA, Luciana. Acontecimento: Reverberações. Belo Horizonte: Autêntica, 2012. p. 213-231.

LOWENTHAL, Leo. The triumph of mass idols. In: . Literature and Mass Culture. New Jersey: Transaction Publishers, 1984. p. 203236.

MARSHALL, P. David. Celebrity and power: fame in contemporary culture. 5. ed. Minneapolis, London: University of Minnesota Press, 2006.

. Celebrity, Politics, and New Media: an Essay on the Implications of Pandemic Fame and Persona. International Journal of Politics, Culture, and Society, v. ?, n. ?, p. 1-16, 2019. MARSHALL, P. David.; REDMOND, Sean. A companion to celebrity. New Dehli: WileyBlackwell, 2016.

MARWICK, Alice.You may know me from YouTube: (micro-)celebrity in socialmedia. In: MARSHALL, P. David; REDMOND, Sean (Ed.). A Companion to Celebrity. Boston: Wiley Blackwell, 2016. p. 333-350. 
MATOS, Marlise. A banalização da violência contra as mulheres e a "cultura do estupro" no Brasil. ÁGORA: Políticas Públicas, Comunicação e Governança Informacional, v. 1, n. 1, p. 01-10, 2016.

MICELI, Sergio. A noite da madrinha: e outros ensaios sobre o éter nacional. São Paulo: Cia das Letras, 2005.

MINOIS, Georges. Histoire de la célébrité. Les trompettes de la renommée. Paris: Perrin, 2012.

MORIN, Edgar. As estrelas: mito e sedução no cinema. Rio de Janeiro: José Olympio, 1989.

\section{MORIN, Edgar. Cultura de massas no século}

XX: o espírito do tempo. Neurose. 9. ed. Rio de Janeiro: Forense, 1997.

PRIMO, Alex. Existem celebridades da e na blogosfera? Reputação e renome em blogs. Líbero, São Paulo, v.12, n. 24, p.107-116, dez. 2009.

QUÉRÉ, Louis. A dupla vida do acontecimento: por um realismo pragmatista. In: FRANCA, Vera R. V.; OLIVEIRA, Luciana. (Org.).

Acontecimento: reverberações. Belo Horizonte: Autêntica, 2012. p. 21-38. Entre o facto e o sentido: a dualidade do acontecimento. Trajectos, Revista de Comunicação, Cultura e Educação, Lisboa, n. 6, p. 59-75, 2005.

Lindividualisation des événements dans le cadre de l'expérience publique. In: BOURDON, Patrice (Org.). Processus du sens. Paris, L'Harmattan, 2000. p. 1-23.

O caráter impessoal da experiência. In: LEAL, Bruno S.; GUIMARÃES, César G.; MENDONÇA, Carlos M. C. (Org.). Entre o sensível e o comunicacional. Belo Horizonte: Autêntica, 2010. p. 19-38.

OLIVEIRA, Pedro Paulo de. A construção social da masculinidade. Belo Horizonte: Editora UFMG; Rio de Janeiro: IUPERJ, 2004. RODRIGUES, José Carlos. Tabu da morte. 2 . ed. rev. Rio de Janeiro: Fiocruz, 2006.

ROJEK, Chris. Celebridade. Rio de Janeiro: Rocco, 2008.

SANDEL, Michael J. Justiça: o que é fazer a coisa certa. Rio de Janeiro: Civilização Brasileira, 2009.

SARMENTO, Rayza; MENDONÇA, Ricardo. Luana, Eliza e a lei Maria da Penha: o acontecimento em discussão.

Contemporânea, v. 15, n. 3, p. 842-865, 2017.

SARMENTO, Rayza. Estudos feministas de mídia e política: uma visão geral. BIB Revista Brasileira de Informação Bibliográfica em Ciências Sociais, São Paulo, v. 87, n. 3, p.181202, 2018.

SERELLE, Marcio V. Inscrições de Che Guevara. In: FRANÇA, Vera R.V.; FREIRE FILHO, João; LANA, Lígia; SIMÕES, Paula G. Celebridades no século XXI: transformações no estatuto da fama. Porto Alegre: Sulina, 2014. p. 159-180.

SILVA, Pâmela. G. Não foi apenas um beijo: $\mathrm{O}$ acontecimento beijo gay na telenovela Amor à Vida e a constituição de públicos. 2016. $163 \mathrm{f}$. Dissertação (Mestrado em Comunicação)Universidade Federal de Minas Gerais, Belo Horizonte, 2016.

SIMÕES, Paula G. 0 acontecimento Ronaldo: a imagem pública de uma celebridade no contexto social contemporâneo. 2012. $282 \mathrm{f}$. 
Tese (Doutorado em Comunicação Social)Faculdade de Filosofia e Ciências Humanas, Universidade Federal de Minas Gerais, Belo Horizonte, 2012a.

. O privado em público: reflexões sobre a construção das celebridades na contemporaneidade. Interin, Curitiba, v. 13, n. 1, p. 1-16, 2012b.

Da morte à biografia de Mandela: acontecimento, celebridade e problema público. Ciberlegenda, n. 31, p. 86-98, 2014. Célebres, anônimos e a morte de Eduardo Campos. In: FRANÇA, Vera R.V.; SIMÕES, Paula G. (Org.). $O$ modelo praxiológico e os desafios da pesquisa em comunicação. 1. ed. Porto Alegre: Sulina, 2018. p. 235-247.

Sobre a morte dos célebres: entre a afetação e a revelação, a invisibilidade da própria morte. In: MARTINS, Moisés de L.; CORREIA, M. da Luz; VAZ, Paulo Bernardo; ANTUNES, Elton (Org.). Sentidos da morte. 1. ed. Curitiba: Editora Appris, 2017. p. 71-86.
SIMOES, Paula G.; FERREIRA, Juliana S. O suicídio de Walmor Chagas: acontecimento e contexto social contemporâneo. In: MARTINS, Moisés de L.; CORREIA, M. da Luz; VAZ, Paulo Bernardo; ANTUNES, Elton (Org.). Figurações da morte nos média e na cultura: entre o estranho e o familiar. 1. ed. Braga/Portugal: CECS, 2016. p. 131-144.

SIMÕES, Paula G.; LIMA, Laula A. O Caso Eliza Samúdio como Acontecimento: fama, anonimato e violência de gênero em nossa sociedade. Observatório, v. 4, n. 1, p. 599629, 2018.

TURNER, Graeme. Understanding Celebrity. London: Thousand Oaks; New Delhi: SAGE, 2004.

WILLIAMS, Rebecca. From Beyond Control to In Control: Investigating Drew Barrymore's Feminist Agency/Authorship. In: REDMOND, Sean; HOLMES, Sue (Ed.). Stardom and Celebrity. Los Angeles/London/New Delhi/ Singapore: Sage, 2007. p. 111-125.

\section{Informações sobre 0 artigo}

Resultado de projeto de pesquisa: "Visibilidade e valores: aparição pública, legitimidade e fama dos sujeitos no cenário midiático-social" (Vera França) e "Observatório de celebridades: emergência, ação e permanência dos famosos no contexto brasileiro" (Paula Simões).

Fontes de financiamento: CAPES, CNPq, FAPEMIG.

Código do processo do projeto financiado: Vera França-CNPq, (Edital PQ-2018, Processo n. 309788/2018-8; CNPq, Edital Universal 2016, 422227/2016-1); Paula Simões-CNPq, (Universal 28/2018, 404740/2018-9); FAPEMIG (Edital 001/2018Demanda Universal, Processo n. APQ-01620-18); CAPES/PRINT (Edital n 41/2017, Processo n. 88887.371217/2019-00). Considerações éticas: não se aplica.

Declaração de conflito de interesses: não se aplica.

Apresentação anterior: texto apresentado no XXVII Encontro da COMPÓS, BELO HORIZONTE/MG, 2018. Agradecimentos/Contribuições adicionais: agradecemos à CAPES, ao CNPq, à FAPEMIG e à PRPq/UFMG 0 apoio ao desenvolvimento de nossas pesquisas. Agradecemos, ainda, aos membros do GRIS/UFMG e do GT Comunicação e Sociabilidade da Compós pelos comentários à versão preliminar deste texto. 


\section{Celebrities, events and values in contemporary society}

\section{Celebridades, acontecimientos y valores en la sociedad contemporánea}

\begin{abstract}
This article seeks to discuss the presence of celebrities in the contemporary scene, considering the actions carried out in events that project them on the public scene and that reveal values of the society. The theoretical framework articulates the notions of celebrities, values and events. The corpus is composed of 18 selected events in an event analysis laboratory from two categories: events that deal with privacy and gender issues. The analysis reveals values-principle that underpin the actions of celebrities, as well as disputes that take place around the affections present in the celebrization of celebrities.
\end{abstract}

\section{Keywords}

Celebrities. Events. Values.

\section{Resumen}

La propuesta de este artículo es reflexionar sobre la presencia de las celebridades en el escena contemporánea, considerando las acciones realizadas en acontecimientos que las proyectan en la escena pública y que revelan los valores de la sociedad. El referencial teórico articula las nociones de celebridades, valores y acontecimientos. El corpus fue construido a partir de un laboratorio de análisis de acontecimientos y se compone de 18 hechos seleccionados teniendo en cuenta dos categorías: acontecimientos que tratan de la vida privada y cuestiones de género. El análisis revela valores-principio que sustentan las acciones de las celebridades, así como las disputas que se procesan en torno de los afectos presentes en la celebrización de los famosos.

\section{Palabras-clave}

Celebridades. Acontecimientos. Valores.

\section{Paula Guimarães Simões}

Doutora pelo Programa de Pós-Graduação em Comunicação da Universidade Ferderal de Minas Gerais. Professora do Programa de Pós-Graduação em Comunicação da Universidade Federal de Minas Gerais e pesquisadora do Grupo de Pesquisa em Imagem e Sociabilidade (GRIS/UFMG). Atualmente, é pesquisadora visitante na University of California, Irvine (UCI). Universidade Federal de Minas Gerais, Belo Horizonte, Minas Gerais, Brasil E-mail: paulaguimaraessimoes@yahoo.com.br ORCID: http://orcid.org/0000-0002-1218-4498

\section{Vera Regina Veiga França}

Doutora em Ciências Sociais pela Université René Descartes - Paris V. Professora do Programa de PósGraduação em Comunicação da Universidade Federal de Minas Gerais. Bolsista Produtividade - Pesquisadora $1 \mathrm{~B}$ do CNPq. Fundadora e pesquisadora do Grupo de Pesquisa em Imagem e Sociabilidade (GRIS/UFMG). Universidade Federal de Minas Gerais, Belo Horizonte, Minas Gerais, Brasil E-mail: veravfranca@yahoo.com.br ORCID: http://orcid.org/0000-0001-6074-4333.

\author{
Contribuição das autoras \\ Concepção e desenho do estudo: \\ Vera França, Paula Simões \\ Aquisição, análise ou interpretação dos dados: \\ Vera França, Paula Simões \\ Redação do manuscrito: Vera França, Paula Simões \\ Revisão crítica do conteúdo intelectual: \\ Vera França, Paula Simões
}

